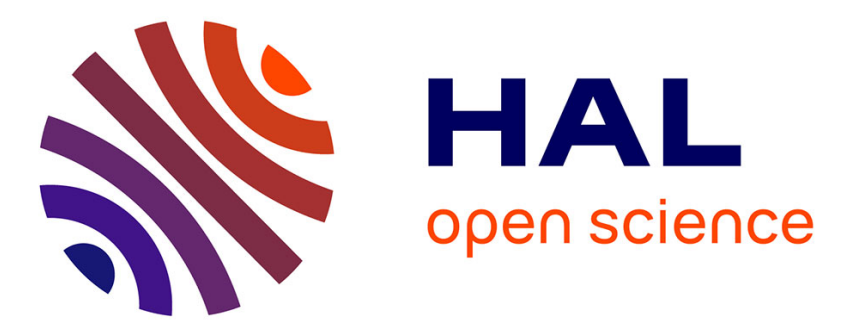

\title{
A LPV Quarter of Car with Semi-active Suspension Model including Dynamic Input Saturation
}

\author{
Jorge de Jesus Lozoya-Santos, Olivier Sename, Luc Dugard, Rubén \\ Morales-Menéndez, Ricardo A. Ramirez-Mendoza
}

\section{To cite this version:}

Jorge de Jesus Lozoya-Santos, Olivier Sename, Luc Dugard, Rubén Morales-Menéndez, Ricardo A. Ramirez-Mendoza. A LPV Quarter of Car with Semi-active Suspension Model including Dynamic Input Saturation. SSSC 2010 - 4th IFAC Symposium on System, Structure and Control, Sep 2010, Ancona, Italy. hal-00504145

\section{HAL Id: hal-00504145 \\ https://hal.science/hal-00504145}

Submitted on $20 \mathrm{Jul} 2010$

HAL is a multi-disciplinary open access archive for the deposit and dissemination of scientific research documents, whether they are published or not. The documents may come from teaching and research institutions in France or abroad, or from public or private research centers.
L'archive ouverte pluridisciplinaire HAL, est destinée au dépôt et à la diffusion de documents scientifiques de niveau recherche, publiés ou non, émanant des établissements d'enseignement et de recherche français ou étrangers, des laboratoires publics ou privés. 


\title{
A LPV Quarter of Car with Semi-active Suspension Model including Dynamic Input Saturation
}

\author{
Jorge de Jesus Lozoya-Santos* Olivier Sename** \\ Luc Dugard ${ }^{* *}$ Ruben Morales-Menendez* \\ Ricardo Ramirez-Mendoza* \\ * Tecnologico de Monterrey, Campus Monterrey, CP 64849 Mexico \\ (e-mail: \{jorge.lozoya,rmm, ricardo.ramirez\}@itesm.mx) \\ ** GIPSA-Lab, Département Automatique, CNRS-Grenoble INP \\ ENSE3, BP 46, F-38402 St Martin d'Hères cedex, France \\ (e-mail: $\{$ olivier.sename, luc.dugard\}@gipsa-lab.grenoble-inp.fr)
}

\begin{abstract}
This paper formulates a Linear Parameter Varying ( $L P V)$ model for a semi-active quarter of car $(Q \circ C)$. The formulation depends on a new $M R$ damper model which is based on the measurement of the maximum deflection velocity. In this device, the saturation is dynamic and it depends on the maximum current to apply and the velocity deflection. One scheduling parameter includes the variation of the damping coefficient and the dynamic saturation of the $M R$ damper decreasing the conservatism of the model. Open and closed loop frequency responses comparison of the proposed model and a nonlinear $Q_{o} C$ are given. The results shows that the new structure for the model is feasible and the nonlinear saturation can be used to weight the controller's output. In both tests, the applied current always is kept realistic.
\end{abstract}

Keywords: semi-active suspension, LPV modelling, experimental validation, MR damper, robust control.

\section{INTRODUCTION}

This paper formulates a Linear Parameter Varying $(L P V)$ model for a semi-active quarter of car. The formulation consists of a $M R$ damper model which is based on the measurement of the maximum deflection velocity. In this device, the saturation is dynamic and it depends on the maximum current to apply and the velocity deflection $\dot{z}$. The scheduling parameter includes the variation of the damping coefficient and the dynamic saturation of the $M R$ damper. The $L P V$ reformulation is based on a modification of the work by Do et al. (2010) and an extension of Poussot-Vassal et al. (2008). The objective is to include the nonlinear dynamic of the $M R$ damper in the $L P V$ model. Several descriptions for the $M R$ damper model, and the cases for nonlinear, linear and LPV model of the quarter of car are given. Then three $H_{\infty}$ controllers are obtained with three linear $Q o C$ models, each corresponding to one scheduling parameter value: low, middle and high damping. As a first approach, the weighting functions of each controller are firstly defined by trial an error based on $a$ priori knowledge of the performance objectives, and their performances are observed.

The section 2 describes the $M R$ damper and the experimental test bench protocol. The semi-active model approach is presented in section 3 . The quarter of car models (nonlinear, linear and LPV) are presented in section 4. The specifications for the simulation in open and closed loop tests are given in section 5 . The results and discussion are presented in section 6 . Section 7 concludes the paper.

\section{THE SEMI-ACTIVE DAMPER}

The selected semi-active damper is a commercial $M R$ damper, which was tested in the automotive laboratory of Metalsa ${ }^{1}$, , see Fig. 1. This damper is a component of the intelligent suspension in the vehicles Cadillac $^{T M} 2009$. The experimental system has three parts: acquisition,

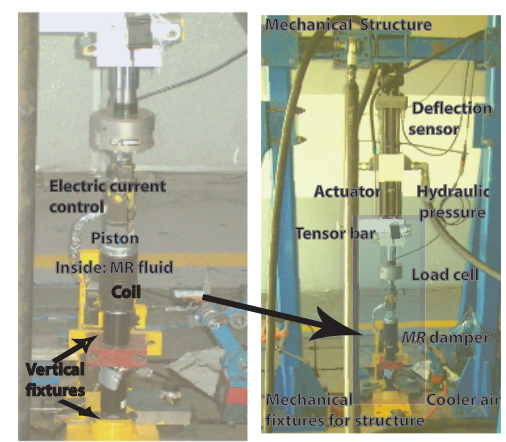

Fig. 1. $M R$ damper and experimental system details.

actuation, and control. The acquisition system captures 3 signals: (a) the displacement, (b) the generated force, and (c) the electric current through the $M R$ damper coil. The system operation is done via a Supervisory Control System (SCS), which it is based on National Instruments ${ }_{T M}$ and LabView ${ }^{T M}$. The actuation system is a $M T S^{T M}$

\footnotetext{
1 www.metalsa.com.mx
} 
Table 1. Nomenclature

\begin{tabular}{|c|c|}
\hline$f_{M R}$ & MR damping force in $N$ \\
\hline$f_{p}$ & Force due to damper mechanics $(N)$ \\
\hline$f_{I}$ & Force due to MR fluid $(N)$ and $I$ \\
\hline$I$ & Applied current to damper coil in $\mathrm{A}$ \\
\hline$t$ & Time \\
\hline$k_{p}$ & Passive stiffness coefficient in $N / m$ \\
\hline$c_{p}$ & Passive damping coefficient in $\mathrm{Ns} / \mathrm{m}$ \\
\hline$c_{I}$ & MR damping coefficient in $N s /(\mathrm{Am})$ \\
\hline$g(\cdot)$ & $\begin{array}{l}\text { Nonlinear function for description } \\
\text { of MR phenomenon }\end{array}$ \\
\hline$m_{s}$ & Sprung mass \\
\hline$m_{u s}$ & Unsprung mass \\
\hline$k_{s}$ & Stiffness coefficient for the suspension spring \\
\hline$k_{t}$ & Wheel tire stiffness \\
\hline$z_{r}$ & Road profile \\
\hline$z_{\text {def }}, \dot{z}_{\text {def }}$ & Damper deflection and velocity in $m$ and $\mathrm{m} / \mathrm{s}$ \\
\hline$z_{s}, \dot{z}_{s}$ & Sprung mass deflection and deflection velocity \\
\hline$z_{u s}, \dot{z}_{u s}$ & Unsprung mass deflection and deflection velocity \\
\hline$\ddot{z}_{\text {def }}$ & Piston deflection acceleration in meters $/ \mathrm{sec}^{2}$ \\
\hline$\ddot{z}_{s}$ & Chassis acceleration in $\mathrm{m} / \mathrm{s}^{2}$ \\
\hline$\ddot{z}_{u s}$ & Tire and strut acceleration in $\mathrm{m} / \mathrm{s}^{2}$ \\
\hline$\zeta_{M R}$ & Damping ratio for MR damper, $f_{M R} / \dot{z}_{d e f}$ \\
\hline$\dot{f}_{M R}$ & Speed of change for $f_{M R}$ \\
\hline$\dot{\zeta}_{M R}$ & the speed of change for $\zeta_{M R}$ \\
\hline$i$ & The $i^{t h}$ sample of the deflection velocity \\
\hline\|\|$\cdot \|_{\infty}$ & The infinity norm of an absolute value \\
\hline$k$ & $\begin{array}{l}\text { number of samples in order to form a regress } \\
\text { vector from the last sampled value } \\
\text { in order to compute }\|\cdot \mid\|_{\infty}\end{array}$ \\
\hline$\nu_{\min }, \nu_{\max }$ & $\begin{array}{l}\text { Minimum and maximum bounds of } \\
\text { sampled } \dot{z}_{\text {def }}\end{array}$ \\
\hline$f_{\text {suspension }}$ & force generated the $Q o C$ semiactive suspension \\
\hline$f_{\text {steering }}$ & force generated for a steering action \\
\hline$f_{\text {spring }}$ & Spring force \\
\hline$I_{\max }$ & $\begin{array}{l}\text { maximum current that can be applied to the } \\
\text { MR damper }\end{array}$ \\
\hline$\omega$ & Frequency in $\mathrm{rad} / \mathrm{s}$ \\
\hline$f: a \mapsto b$ & $\begin{array}{l}\text { The function } f \text { maps the element } a \text { to } \\
\text { the element } b\end{array}$ \\
\hline$a_{i, j}$ & $\begin{array}{c}\text { Coefficients for the benchmark MR damper model } \\
\text { where } i=\{1,2, \ldots, 5\} \text { and } j=\{1,2\}\end{array}$ \\
\hline
\end{tabular}

equipment that includes: an actuator of 3000 PSI with a $15 \mathrm{~Hz}$ bandwidth, a controller hardware unit Flextest GT, a software Station Manager ${ }^{T M}$ and a MultiPurpose TestWare $^{T M}$. The load capacity is $25 \mathrm{KN}$ at 3,000 psi. The stroke is $150 \mathrm{~mm}$. The span of the piston deflection is $\pm 12.5 \mathrm{~mm}$. An electric current driver adjusts the electric current. The span of the electric current command is from 0 to $2.5 \mathrm{~A}$.

The experiment for modelling issue is described below. The inputs are: the displacement defined as the movement of the damper piston, and the electrical current through the coil. The output is the force delivered by the damper according to the inputs. The experiment has a displacement with an amplitude modulated and increased clock period signal - (ICPS) electric current. A total of 10 frequencies were tested in the span $1.40-14 \mathrm{~Hz}$, see Fig. 2. For details on experiments see Lozoya-Santos et al. (2009).

\section{SEMI-ACTIVE DAMPER MODELLING}

The magneto-rheological damper can be described by a dynamical model according to the following statemens:
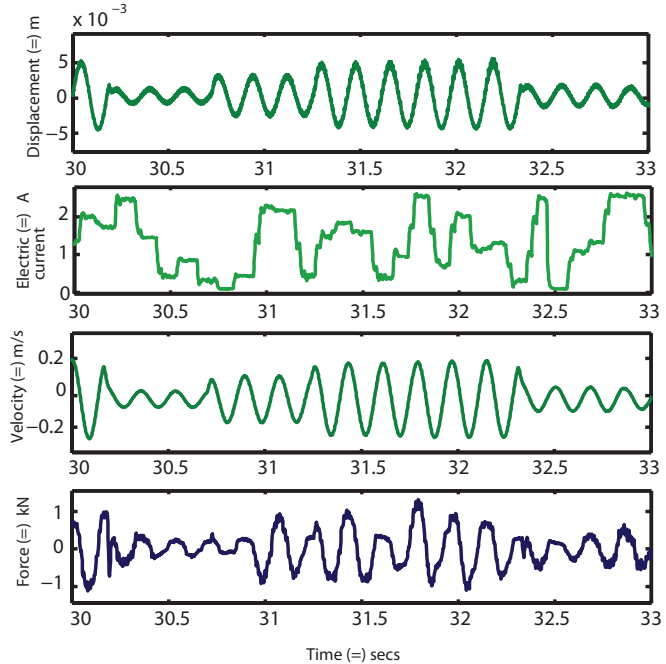

Fig. 2. Experimental dataset fragment from experiment 1.

Let \|\|$\dot{Z}_{\text {def }} \mid\left\|_{\infty}:\right\| \dot{z}_{\text {def }}\|\|_{\infty} \in\left[\nu_{\min }, \nu_{\max }\right], \mathcal{I}: I \in$ $\left[\iota_{\text {min }}, \iota_{\text {max }}\right], \mathcal{F}_{M R}: f_{M R} \in\left[\mathcal{F}_{\text {min }}, \mathcal{F}_{\text {max }}\right]$,

When $\dot{z}_{\text {def }}=0$,

(1) $f_{p}=0$

(2) $f_{I}=0$

(3) $f_{\operatorname{Imax}}=0$

(4) $\left|f_{M R}\right|=\left|f_{p}+f_{I}\right|$

When $\dot{z}_{\text {def }} \neq 0$,

(1) $\left|f_{M R}\right| \propto\left|f_{p}+f_{I}\right|$

(2) $\left|f_{I}\right| \propto I$

(3) $f_{I \max }=c_{I} \cdot I_{\max } \cdot g\left(z_{\text {def }}, \dot{z}_{\text {def }}\right)$

(4) $\sup \left\{\left|f_{M R}\right| \in \mathcal{F}_{M R}: f_{M R}<\mathcal{F}_{\max }\right\}=\left|f_{p}+f_{\text {Imax }}\right|$

(5) $\inf \left\{\left|f_{M R}\right| \in \mathcal{F}_{M R}: f_{M R}>f_{p}\right\}=\left|f_{p}\right|$

Therefore, (1) describes a damper's behavior with a $M R$ fluid, where it is equivalent to put in parallel two dampers: a passive damper, and a dynamic damper in the sense of a variable damping coefficient. The sum of these components conforms the $M R$ total damping force $f_{M R}$.

$$
\begin{aligned}
f_{M R} & =f_{p}\left(z_{\text {def }}, \dot{z}_{\text {def }}\right)+f_{I}\left(z_{\text {def }}, \dot{z}_{\text {def }}, I\right) \\
f_{p} & =k_{p} z_{\text {def }}+c_{p} \dot{z}_{\text {def }}, \quad f_{I}=c_{I} \cdot I \cdot g\left(z_{\text {def }}, \dot{z}_{\text {def }}\right)
\end{aligned}
$$

It is assumed that the saturation is present in both, the applied electric current, and in $g(\cdot)$.

The maximum deflection velocity is a function of the maximum amplitude and the frequency of the deflection, Bastow et al. (2004), hence this measure is proposed as a direct indicator of the damping coefficient. The model is based on the variation of the damping coefficient depending on the maximum deflection velocity which can be measured in real time. Figure 3 shows how the damping coefficient changes with deflection velocity and the $M R$ force.

For deflection velocities below $0.07 \mathrm{~m} \mathrm{~s}$, the speed of change of the velocity and the force are almost the same. Hence, $\zeta_{M R}$ has a ramp behavior. For deflection velocities over $0.1 \mathrm{~m} \mathrm{~s}, \ddot{z}_{\text {def }}$ begins to be bigger regarding $\dot{f}_{M R}$. This phenomenon occurs due to the wearing down of the 


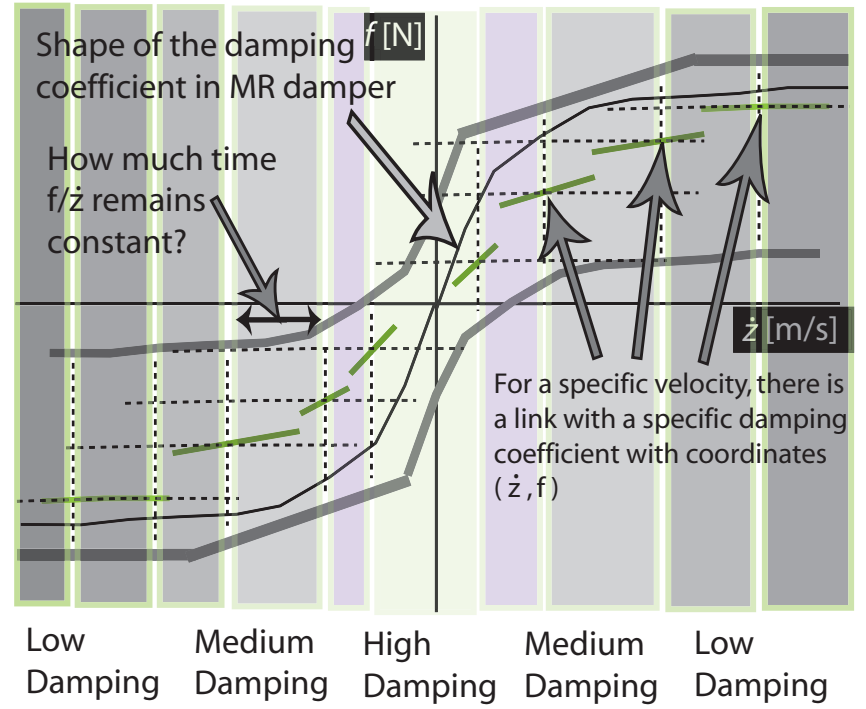

Fig. 3. The damping coefficient is the instantaneous quotient between the $M R$ force and the deflection velocity. The darker zone, the lower damping coefficient.

magnetic chains in the oil. In this phase, $\dot{\zeta}_{M R}$ becomes smaller while $\dot{z}_{\text {def }}$ grows. Hence, when $\zeta_{M R}$ is observed in the instant $t$, its value can be estimated in a time boundary where the deflection velocity has not a significant change.

Let $\zeta_{M R}: I, g\left(z_{\text {def }}, \dot{z}_{\text {def }}\right) \mapsto f_{I}$ denoted by $\zeta_{M R}=f_{I} / \dot{z}_{\text {def }}$ such that:

$$
\begin{gathered}
\frac{f_{I}}{\dot{z}_{\text {def }}}=\frac{I \cdot c_{I} \cdot g\left(z_{\text {def }}, \dot{z}_{\text {def }}\right)}{\dot{z}_{\text {def }}} \\
g\left(z_{\text {def }}, \dot{z}_{\text {def }}\right)=\frac{\dot{z}_{\text {def }}}{\|\mid\| \dot{z}_{\text {def }} \|_{\infty_{i-k}^{i}}^{i}}
\end{gathered}
$$

Hence, by substituing (3) in (2) and solving for $f_{I}$,

$$
f_{I}=c_{I} \cdot I \cdot \dot{z}_{\text {def }} \cdot \frac{1}{\left\|\dot{z}_{\text {def }}\right\|_{\infty_{i-k}}^{i}}
$$

From (1) and (4), the Maximum Deflection Velocity (MDV) $M R$ damper model is:

where,

$$
f_{M R}=k_{p} z_{d e f}+c_{p} \dot{z}_{d e f}+I \cdot \dot{z}_{d e f} \cdot c_{I} \cdot \rho
$$

The model has only four parameters. Note that the current input of the model is applied in a linear manner, an important characteristic for controller synthesis.

\section{VERTICAL QUARTER OF CAR QOC}

The system consists of a vertical model of a Quarter of Car $\left(Q_{o} C\right)$. It is assumed that the wheel contact is kept. A semi-active damper and a spring built the suspension between masses. The dynamical equations of a quarter of vehicle are governed by:

$$
\begin{aligned}
& m_{s} \ddot{z}_{s}=-f_{\text {spring }}-f_{M R}+f_{\text {steering }} \\
& m_{u s} \ddot{z}_{u s}=f_{\text {spring }}+f_{M R}-k_{t}\left(z_{u s}-z_{r}\right)
\end{aligned}
$$

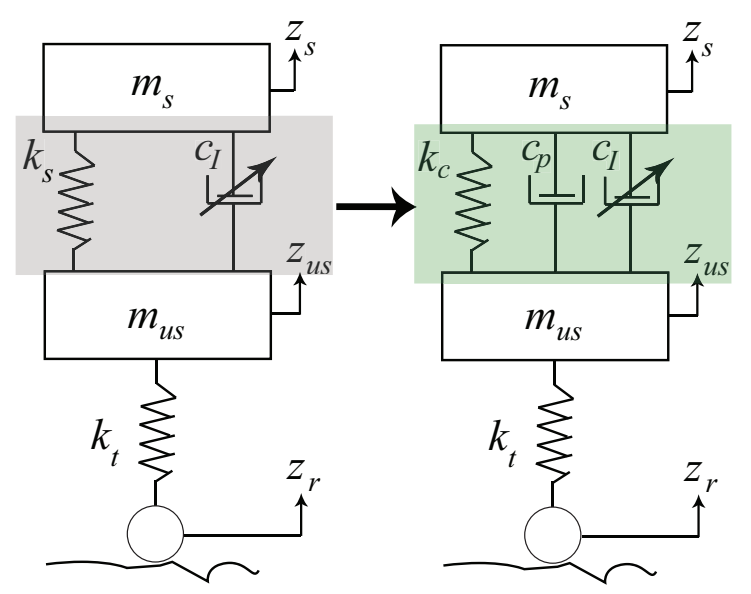

Fig. 4. Model for a quarter of vehicle with a semi-active damper. Left diagram shows the typical suspension model. Right diagram shows the proposed suspension model. $k_{c}$ is the sum of $k_{s}$ and $k_{p}$.

\subsection{LPV QoV}

The representation of a $Q o C$ is modeled in the $L P V$ framework by defining a $M R$ damper as in (6), see Fig. 4. The state-space $Q_{o} C L P V$ representation

$$
\begin{gathered}
{\left[\begin{array}{c}
\dot{z}_{s} \\
\ddot{z}_{s} \\
\dot{z}_{u s} \\
\ddot{z}_{u s}
\end{array}\right]=A\left[\begin{array}{c}
z_{s} \\
\dot{z}_{s} \\
z_{u s} \\
\dot{z}_{u s}
\end{array}\right]+B_{1} \rho \cdot u+B_{2} \cdot z_{r}+B_{3} \cdot F_{d z}} \\
y=C\left[\begin{array}{c}
z_{s} \\
\dot{z}_{s} \\
z_{u s} \\
\dot{z}_{u s}
\end{array}\right]+D\left[\begin{array}{c}
u \\
z_{r} \\
F_{d z}
\end{array}\right]
\end{gathered}
$$

where,

$$
A=\left[\begin{array}{cccc}
0 & 1 & 0 & 0 \\
\frac{-k_{s}-k_{p}}{m_{s}} & -\frac{c_{p}}{m_{s}} & \frac{k_{s}+k_{p}}{m_{s}} & \frac{c_{p}}{m_{s}} \\
0 & 0 & 0 & 1 \\
\frac{k_{s}+k_{p}}{m_{u s}} & \frac{c_{p}}{m_{u s}} & \frac{-k_{s}-k_{p}-k_{t}}{m_{u s}} & -\frac{c_{p}}{m_{u s}}
\end{array}\right]
$$

$$
\begin{aligned}
B_{1} & =\left[\begin{array}{c}
0 \\
-\frac{c_{I}}{m_{s}} \\
0 \\
\frac{c_{I}}{m_{u s}}
\end{array}\right], u=\dot{z}_{\text {def }} \cdot I, \\
B_{2}= & {\left[\begin{array}{c}
0 \\
0 \\
0 \\
\frac{k_{t}}{m_{u s}}
\end{array}\right], B_{3}=\left[\begin{array}{c}
0 \\
\frac{1}{m_{s}} \\
0 \\
0
\end{array}\right], C=\left[\begin{array}{c}
1 \\
0 \\
-1 \\
0
\end{array}\right]^{T}, D=0 }
\end{aligned}
$$

In (9) the control input matrix $B_{1} \rho$ is parameter dependent, a not consistent feature for $L P V / H_{\infty}$ controller synthesis, Apkarian and Gahinet (1995). By adding a strictly proper filter to the input $u$ of $(9)$, the controlled input matrix becomes independent of $\rho$, see Poussot-Vassal et al. (2008). The state-space $F$ is given in (10), where $A_{f}, C_{f}$, and $C_{f}$ are constant matrices. 


$$
F:\left(\begin{array}{c}
\dot{x}_{f} \\
u_{f}
\end{array}\right)=\left[\begin{array}{cc}
A_{f} & B_{f} \\
C_{f} & 0
\end{array}\right]\left(\begin{array}{l}
x_{f} \\
u_{c}
\end{array}\right)
$$

4.2 Reformulation for LPV model taking into account the input saturation and the system semi-activeness

Given that the syntheses of $H_{\infty}$ controllers do not guarantee a controller output with the same sign on the velocity $\dot{z}_{\text {def }}$, described as the dissipativity constraint, active forces could be generated by the $H_{\infty}$ controller. Therefore, a saturation function is proposed to keep the property of semi-activeness, see Fig. 5.

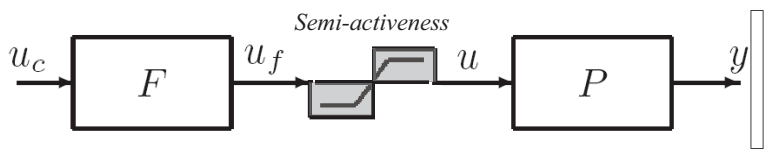

Fig. 5. Model with a semi-active bounded input saturation.

Let $U: u \in\left[v_{\min }, v_{\max }\right]$, defined by $u=I \dot{z}_{\text {def }}$, and

$$
\begin{aligned}
& v_{\min }=-v_{\max } \\
& v_{\max }=\iota_{\max } \cdot\left\|\dot{z}_{\text {def }}\right\| \|_{\infty_{i-k}^{i}}
\end{aligned}
$$

Hence, $v_{\min }$ and $v_{\max }$ will vary according to the maximum deflection velocity in the last $k$ samples, and the saturation is dynamic depending on $\dot{z}_{\text {def }}$. The saturation approach for control input consists on to bound the semi-active damper input, according to eqn. (11).

$$
u=\operatorname{sat}\left(u_{f}\right)=\left\{\begin{array}{c}
0 \quad \text { if } \operatorname{sign}\left(u_{f}\right) \neq \operatorname{sign}\left(\dot{z}_{\text {def }}\right) \\
v_{\max }, \quad \text { if } u_{f}>v_{\max } \\
\text { and } \operatorname{sign}\left(u_{f}\right)=\operatorname{sign}\left(\dot{z}_{\text {def }}\right) \\
u_{f}, \quad \text { if } v_{\min } \leq u_{f} \leq v_{\max } \\
\quad \text { and } \operatorname{sign}\left(u_{f}\right)=\operatorname{sign}\left(\dot{z}_{\text {def }}\right) \\
v_{\min } \quad \text { if } u_{f}<v_{\min } \\
\text { and } \operatorname{sign}\left(u_{f}\right)=\operatorname{sign}\left(\dot{z}_{\text {def }}\right)
\end{array}\right.
$$

In order to remain in the LPV framework, the saturation function $s a t\left(u_{f}\right)$ is proposed as a hyperbolic tangent function as in Do et al. (2010):

$$
\begin{aligned}
& I_{\max } \cdot\||| \dot{z} \mid\|_{\infty_{i-k}^{i}}^{i} \cdot \tanh \left(\frac{u_{f}}{I_{\max } \cdot\||| \dot{z} \mid\|_{\infty}^{i}{ }_{i-k}}\right) \text {, or } \\
& I_{\max } \cdot\||\dot{z}|\|_{\infty_{i-k}^{i}} \cdot \tanh \left(\frac{C_{f} x_{f}}{I_{\max } \cdot\||| \dot{z} \mid\|_{\infty_{i-k}^{i}}}\right)
\end{aligned}
$$

Finally, the state space representation for the transfer function $u_{/} u_{c}$ is:

$$
F_{1}:\left(\begin{array}{c}
\dot{x}_{f} \\
u
\end{array}\right)=\left[\begin{array}{cc}
A_{f} & B_{f} \\
C_{f} \rho_{\text {sat }} & 0
\end{array}\right]\left(\begin{array}{c}
x_{f} \\
u_{c}
\end{array}\right)
$$

where $\rho_{\text {sat }}=\frac{\tanh (\alpha)}{\alpha}$ and $\alpha=\frac{C_{f} x_{f}}{I_{\max } \cdot\left(\|\dot{x}\|_{\infty}^{i}{ }_{i-k}\right)}$

The system (9) does not take into account the saturation in $u$. A reformulation is proposed by adding the saturated actuator defined by (11), following the structure in Fig. 5 and following the ideal linear design adding the filter given in (12), the new $L P V$ system (13) is defined by the scheduling variable $\rho^{*}=\rho \cdot \rho_{\text {sat }}$ :

$$
\begin{aligned}
& \dot{x}=A\left(\rho^{*}\right) x+B u_{c}+B_{1} w \\
& y=C x
\end{aligned} .
$$

where,

$$
\begin{aligned}
& x=\left(x_{s}^{T} x_{f}^{T}\right)^{T}, \quad A\left(\rho^{*}\right)=\left[\begin{array}{cc}
A_{s} & \rho^{*} B_{s} C_{f} \\
0 & A_{f}
\end{array}\right], \\
& B=\left(\begin{array}{c}
0 \\
B_{f}
\end{array}\right), \quad B_{1}=\left(\begin{array}{c}
B_{s 1} \\
0
\end{array}\right), \quad C=\left(\begin{array}{c}
C_{s} \\
0
\end{array}\right)^{T}
\end{aligned}
$$

\section{SIMULATION}

The $Q o C$ parameters corresponds to a Renault Megane

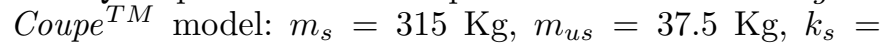
$29500 \mathrm{~N} / \mathrm{m}, k_{t}=210000 \mathrm{~N} / \mathrm{m}$. The steering force is considered as zero. The $Q_{o} C$ becomes nonlinear due to the use of a semi-active suspension. The suspension is simulated through two approaches. The objective is to observe the controllability margins of the suspension in the frequency response. The first approach uses two static models of the $M R$ damper. The second one uses the LPV $M R$ damper model (13) and the saturation function (11).

5.1 First approach: QoV with two static MR damper model in the suspension (QoV-2SMR)

In the first approach, the $M R$ damper consists of a passive damper in series with an i-driven damper. Both models have the structure presented in Guo et al. (2006):

$$
\begin{aligned}
f_{d j}= & a_{1, j} \cdot \tanh \left(a_{2, j} \dot{x}+a_{3, j} x\right) \\
& +a_{4, j} \dot{x}+a_{5, j} x
\end{aligned}
$$

The static models were identified with the experimental dataset 1, Lozoya-Santos et al. (2009), with 0 A and 2.5 A, respectively, see Fig. 6. The force in the experimental dataset does not contain the force generated by the MR damper actuated with $0 \mathrm{~A}$. This force was removed by subtraction. In this manner, 10 parameters were identified, 5 of them corresponding to the passive damper $(j=1)$ being: $\theta_{1}=\left[\begin{array}{lllll}131.4 & 321.8 & 153.5 & 603.9 & -2450.9\end{array}\right]$. The 5 parameters that correspond to the I-driven damper, $(j=$ 2), are: $\theta_{2}=\left[\begin{array}{lllll}1668.5 & 2.1 & 5.1 & -994 & 612.2\end{array}\right]$. Hence, from

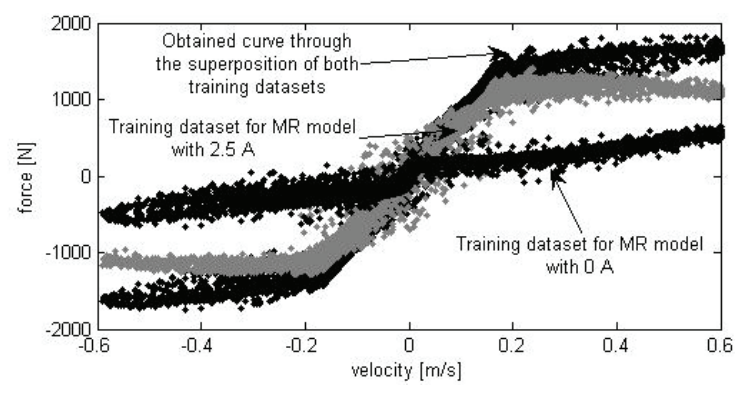

Fig. 6. Experimental static map for suspension damping for 0 and 2.5 Amperes.

a linear stiffness and two static $M R$ damper models, the nonlinear force generated by the suspension is computed as:

$$
\begin{gathered}
f_{\text {suspension }} \approx k_{s} \cdot z_{\text {def }}+\text { passive damper }+ \\
b \cdot I-\text { driven damper }
\end{gathered}
$$

Where $b$ is the percentage of $M R$ damping force, and this variable is linear with the current to apply, with a maximum value of $\mathrm{I}=2.5 \mathrm{~A}$. When the $M R$ dissipative force is lower than the passive dissipative force (passive damper), the current to apply is zero. 
5.2 Second approach: QoV with static MR damper map $\left(u=I \cdot \dot{z}_{d e f}, f_{M R}\right)$ in the suspension (QoV-u)

The $M R$ damper consists of the aforementioned static model and a static mapping, Fig. 7 , where $u$ is the product of the applied current and deflection velocity. The static map shows a quasi linear relation between the product $I \cdot \dot{x}$ and the dissipative $M R$ force. Each line shows the force generated by $I=\{0.44,0.8,1.2,1.6,2.1,2.5\}$. Hence the nonlinear force generated by the suspension is computed as:

$$
\begin{aligned}
f_{\text {suspension }} \approx & k_{s} \cdot z_{\text {def }}+\text { passive damper }+ \\
& \text { interpolation }\left(U_{M R}, F_{M R}, u\right)
\end{aligned}
$$

where $U_{M R}, F_{M R}$ defines the static map $u$ versus $f_{M R}$.

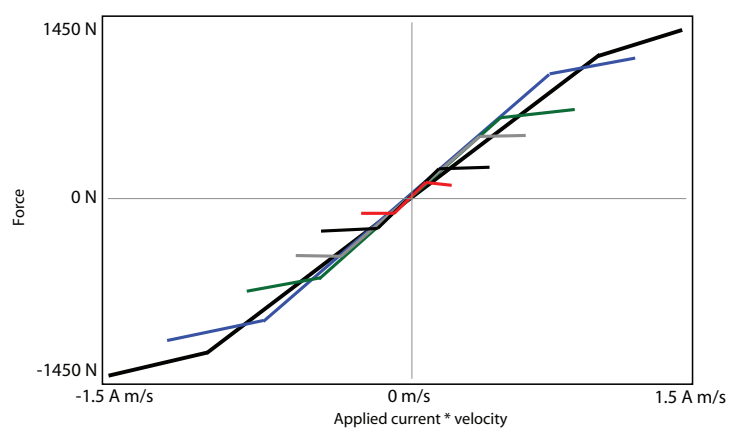

Fig. 7. Nonlinear map for suspension $M R$ damping.

\subsection{Open loop tests}

The configuration for the first approach open loop test specifies a constant current as input, see Fig. 8, (top plot). The tested current values are $I=\{0.01,0.25,0.5,0.75,1.0$, $1.25,1.5,1.75,2.0,2.25,2.5\}$. Hence, this simulation assumes that the controller will always deliver semi-active command. The input neither take into account the dynamic saturation nor the semi-activeness of the system given that two static $M R$ damper models are included in the $Q o C . \rho$ is the scheduling parameter when using this nonlinear $Q_{o} C$ for controller evaluation.

The second approach open loop test, see Fig. 8, (bottom plot), specifies $u_{f}$ being the product $\left(I \cdot \dot{z}_{\text {def }}\right)$ as system input. The tested values span are $u_{f}=\{-2.5,2.5\}$ begining in -2.5 with increments of $\Delta\left(u_{f}\right)=0.25$. Hence, this simulation does not assume a controller command into the semi-activeness area. In order to take care of the dynamic saturation and in the semi-activeness of the system, the equation (11) is included. $\rho^{*}$ is the scheduling parameter when using this nonlinear $Q_{o} C$ for controller evaluation.

\subsection{Closed loop test: Mixed Sky-Hook and Acceleration -Driven-Damper (SHADD) control}

This control is proposed in Savaresi and Spelta (2007). It has been demonstrated that $S H A D D$ control is optimal in the sense that it minimizes the vertical body acceleration $\ddot{z}_{s}$ when no road-preview is available. The $S H A D D$ control varies the input $I_{i n}$ as follows:
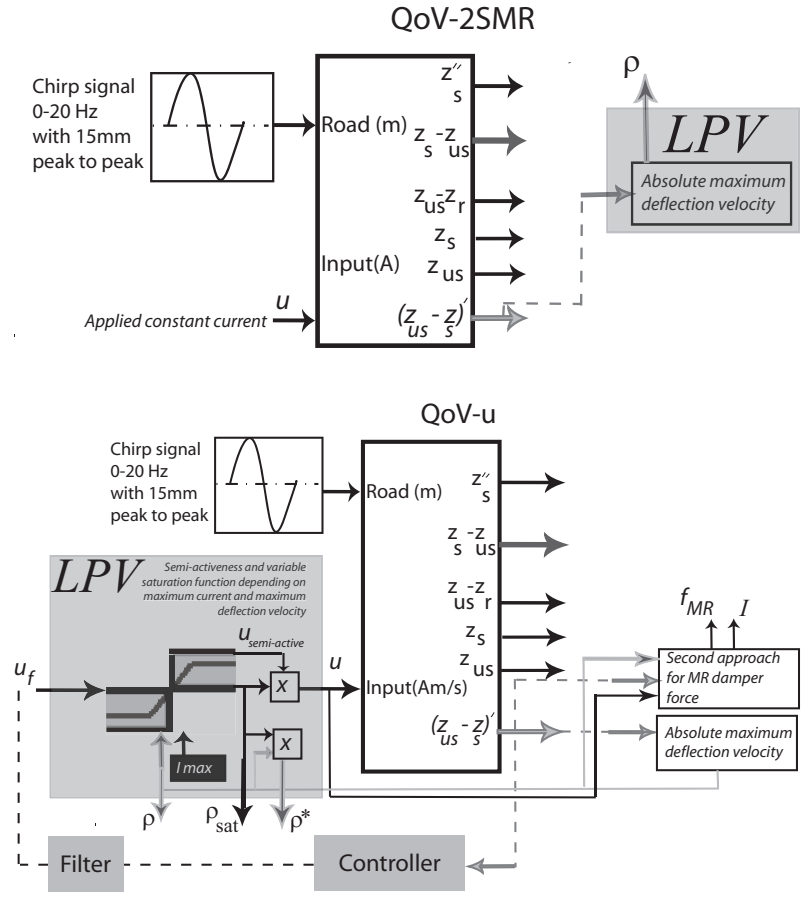

Fig. 8. Frequency test for the nonlinear QoC. QoV-u includes a external model (16) for the $M R$ damping force computation. The black dashed line indicates the controller feedback for closed loop simulation.

$$
u_{S H A D D}=\left\{\begin{array}{c}
I_{\min } \cdot z_{\text {def }} \\
\text { if }\left(\ddot{z}_{s}^{2}-\alpha^{2} \dot{z}_{s}^{2} \leq 0\right) \&\left(\dot{z}_{s}^{2} \cdot \dot{z}_{\text {def }}^{2}>0\right) \\
\|\left(\ddot{z}_{s}^{2}-\alpha^{2} \dot{z}_{s}^{2}>0\right) \&\left(\dot{z}_{s}^{2} \cdot \dot{z}_{\text {def }}^{2}>0\right) \\
I_{\max } \cdot \ddot{z}_{\text {def }} \\
\text { if }\left(\ddot{z}_{s}^{2}-\alpha^{2} \dot{z}_{s}^{2} \leq 0\right) \&\left(\dot{z}_{s}^{2} \cdot \dot{z}_{\text {def }}^{2} \leq 0\right) \\
\|\left(\ddot{z}_{s}^{2}-\alpha^{2} \dot{z}_{s}^{2}>0\right) \&\left(\dot{z}_{s}^{2} \cdot \dot{z}_{\text {def }}^{2} \leq 0\right)
\end{array}\right\}
$$

For a standard automotive suspension, $\alpha$ can be chosen around $11 \mathrm{rad} / \mathrm{s}(1.8 \mathrm{~Hz})$ which is the natural peak frequency to handle in comfort oriented suspensions. $u_{S H A D D}$ is proposed as the product $I \cdot z_{\text {def }}$ in order to cope with the $Q o V-u$ scheme.

\subsection{Closed loop test: $H_{\infty}$ control for three damping zones}

The LPV equation (13) is the generic form of the $M R$ damper behavior, hence three values of $\rho$ have been chosen in order to evaluate three LTI controllers. These values are $\rho=\{2,4,10\}$ and they are linked to maximum velocity deflections $\dot{x}=\{0.5,0.2,0.1\} \mathrm{m} / \mathrm{s}$. This means that the suspension works for each LTI controller in the following damping coefficient $\zeta_{M R}$ modes: low (730 Ns/Am), medium (1460 Ns/Am) and high (3850 Ns/Am).

For any system, the $H_{\infty}$ control synthesis is a disturbance attenuation problem. It consists in finding a stabilizing controller that minimizes the impact of the input disturbances $w$ on the controlled output $z$. The solution to find the controller is the LMI based Degree of Freedom $H_{\infty}$ control synthesis, Poussot-Vassal et al. (2008). In this paper, the measured variable is defined as $\dot{z}_{\text {def }}$. The controlled outputs are the $\ddot{z}_{s}$ and $z_{u s}$, see Figure 9 . The weighting functions of each controller are defined by trial an error based on a priori knowledge of the performance objectives, 
being these:

$$
\begin{aligned}
& W_{\ddot{z}_{s}}=\frac{\text { Gain }_{s} \cdot \omega_{0}^{2}}{\omega_{0}^{2}+2 \zeta \omega_{0} s+s^{2}} \text { for } f_{s}=1 \mathrm{~Hz}, \zeta=0.7, \text { and } \text { Gain }_{s}=1 \\
& W_{z_{u s}}=\frac{\text { Gain }_{u s} \cdot \omega_{0 u s}}{s+\omega_{0 u s}} \text { for } f_{u s}=0.3 \mathrm{~Hz}, \text { and } \text { Gain }_{u s}=0.3 \\
& W_{z_{r}}=3 \times 10^{-2}
\end{aligned}
$$

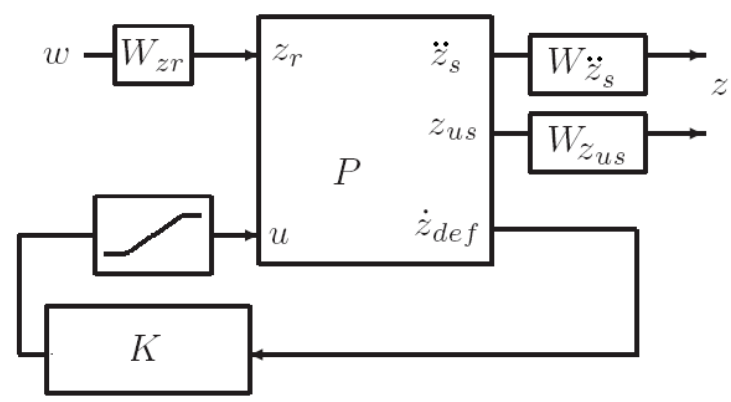

Fig. 9. $H_{\infty}$ approach for a $L T I$ QoV.

Remark. It is important to note that the controller's output is weighted by the dynamic saturation formulation, using the maximum velocity $\dot{z}_{\text {def }}$, before the command inputs the $Q o V-u$. Therefore, the controller consists of the controller approach plus the dynamic saturation.

\section{RESULTS}

\subsection{Performance specifications.}

The controllers used to evaluate the QoV-u are SHADD (feasible controller in commercial vehicles), and $H_{\infty}$ approaches, whose design is based on a tradeoff between comfort and road holding. The performance specifications for the $Q_{o} C$ are defined as follows:

- Comfort: In the span of [0-20] Hz, the maximum gain of the frequency response $\ddot{z}_{s} / z_{r}$ must be kept low, i. e. below 200. In $[0-2] \mathrm{Hz}$ the human being can feel dizziness and motion sickness. From $2-12 \mathrm{~Hz}$ an overall discomfort is influenced by sensations in different parts of the body. The dangerous vibrations of the head with respect to shoulders happen in the span from 14-20 Hz, Bastow et al. (2004). The maximum gain of the frequency response $z_{s} / z_{r}$ must be kept below 1.8 in the span [0-2] hz.

- Road holding : The frequency response $\left(z_{u s}-z_{r}\right) / z_{r}$ ideally must stand close to 0 (zero).

- Suspension deflection: A constraint on the deflection of the actuator $z_{d e f} / z_{r}$ is hold between 0 and $20 \mathrm{~Hz}$ in order to preserve the lifetime cycle.

It is important to remark that the controllers output is the current applied to the coil, a not common output in the topic literature. In the case of the $H_{\infty}$ controllers, the absolute value of $u$ is divided between the actual $\dot{z}_{d} e f$, with the constraints $0 \leq I \leq 2.5 \mathrm{~A}$. In order to avoid undefined numbers, an $\epsilon=1 e-10$ is added to the velocity $u$. For the frequency responses in open and closed loop tests the pseudo-bode computation presented in Savaresi et al. (2003) was used.
6.2 Open Loop Frequency response of the quarter-car with the MR damper

According with the aforementioned specifications, the controllability of the semi-active suspension is discussed in the next subsections.

Regarding to the comfort oriented transfer function $\ddot{z}_{s} / z_{r}$ :

QoV-2SMR. For frequencies between 0 and $2 \mathrm{~Hz}$, see Fig. 10 top plot, a comfort condition and good handling are achieved with currents greater than $1 \mathrm{~A}$, and with $0 \mathrm{~A}$ in the range from $2-12 \mathrm{~Hz}$, and from $14-20 \mathrm{~Hz}$. In the span $12-14 \mathrm{~Hz}$ due to the tire-hop frequency, the applied current does not make big difference. Hence the conclusion is that this approach is sensitive to this performance, limited in the span $12-14 \mathrm{~Hz}$.

QoV-u. In Fig. 10, bottom plot, with an $u \approx 0 \mathrm{Am} / \mathrm{s}$, the comfort condition and good handling are achieved in 0$3.5 \mathrm{~Hz}$. In the frequency span $5-8 \mathrm{~Hz}, Q o V-u$ behaves equals than $Q o V-2 S M R$. In [7-12,14-20] Hz the QoV$u$ has higher gains. From 12 to $14 \mathrm{~Hz}$, the deflection velocities are the highest of the interest bandwidth. Therefore, for high currents (high $u$ ) the gain is low with an excellent performance. In the last range from 14-20 Hz, small values of $u$ are better.
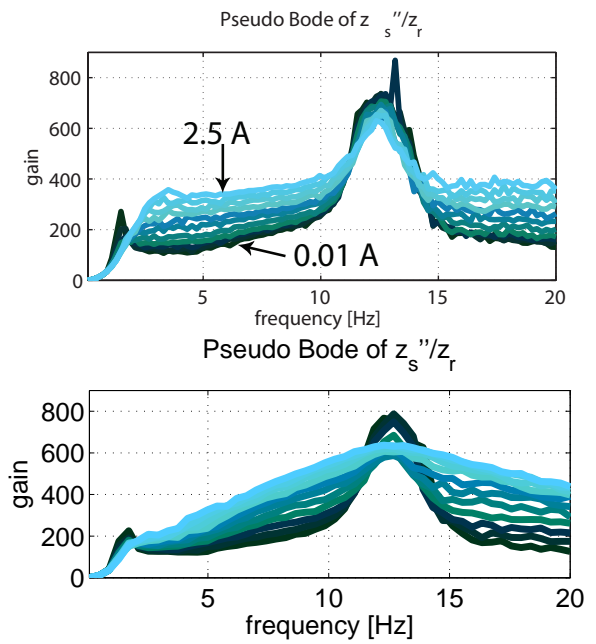

Fig. 10. Frequency response for open loop test for the simulation of the nonlinear $\mathrm{QoV}$ on the comfort key transfer function.

Regarding to the road holding oriented transfer function $\left(z_{u s}-z_{r}\right) / z_{r}$ :

QoV-2SMR. From 0-2 Hz, 2.5 A meet the industrial specifications, from $2-8 \mathrm{~Hz}, 0 \mathrm{~A}$ keeps low the gain, and in the rest of the bandwidth, again $2.5 \mathrm{~A}$ is desirable to allow the road holding, see Figure 11, top plot.

QoV-u. Figure 11, bottom plot, the $z_{d}$ ef gains is closer to the observed for $Q o V$-2SMR. The difference is the obtained span in the gain of the transfer function for [10-15] Hz, QoV-u shows an excellent control range. This configuration covers a set of gain values (close to 1 ) where higher currents can assure the road holding.

For the suspension lifetime:

QoV-2SMR. This performance objective is improved by holding higher current below $3 \mathrm{~Hz}$ and between 11-15 


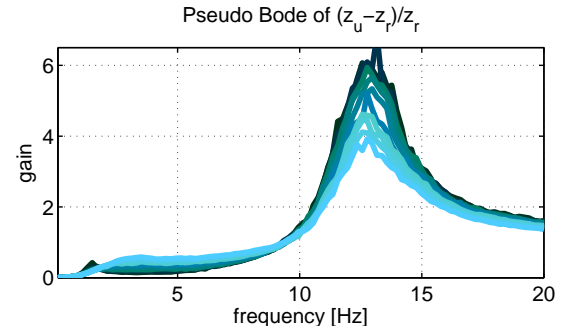

Pseudo Bode of $\left(z_{u}-z_{r}\right) / z_{r}$

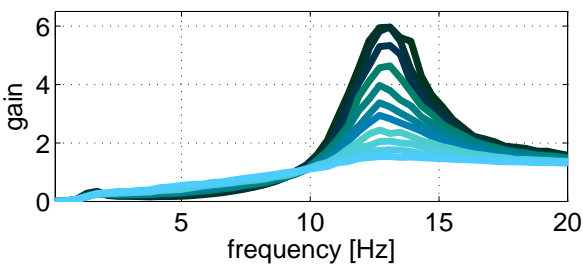

Fig. 11. Frequency response for open loop test for the road holding key transmissibilities

Hz. In the span from $3-11 \mathrm{~Hz}$ and $15-20 \mathrm{~Hz}$, the applied current has no influence on this objective, see Fig. 12, top plot.

QoV-u. The gain is limited with low values of $u$ from 0 $12 \mathrm{~Hz}$ and $14-20 \mathrm{~Hz}$. This possibly means that currents between 1-1.7 A are proper for the suspension lifetime.
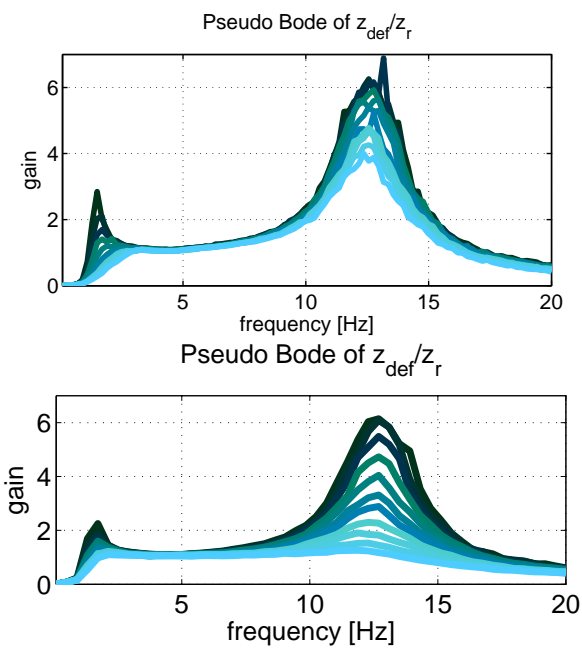

Fig. 12. Frequency response for open loop test for the simulation of the suspension deflection of the nonlinear QoV.

The simulation results show that the proposed configuration for the control input $u=I \cdot \dot{z}_{\text {def }}$ could explore in a deep manner the controlability of the semiactive suspension.

\subsection{Closed Loop Frequency response of the quarter-car with the MR damper}

Comfort. For primary ride [0-2] Hz, SH-ADD achieves the control objective in $z_{s}$ while the $H_{\infty}$ controllers overpass the healthy level of 1.8 gain. In secondary ride $[2-10] \mathrm{Hz}$, the controllers deliver good level of perfomance for the $\ddot{z}_{s}$, specially the $H_{\infty}$ controller for $\zeta_{M R}$ low. According to the results shown in Do et al. (2010); Savaresi and Spelta (2007), Fig. 13, the LPV controllers are more consistents in the whole interest bandwidth, [0-20] $\mathrm{Hz}$ while the evaluated controllers can not drive the $Q o V-u$ 's non linearities.

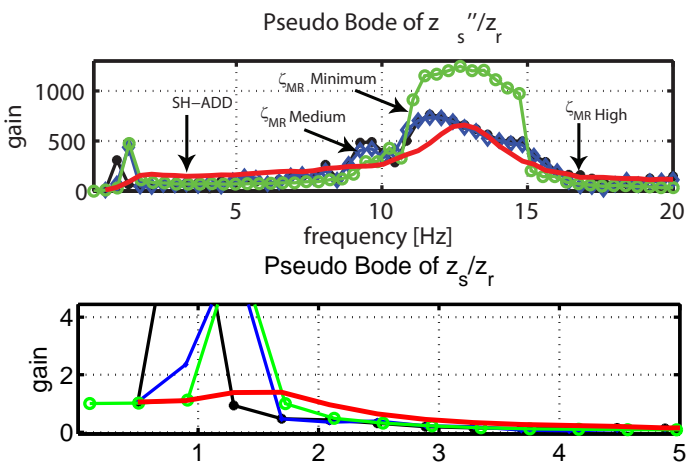

Fig. 13. Pseudobodes for the performance objectives.

Road holding and suspension deflection. The

$S H$ - $A D D$ exposes good performance for the lifetime of the suspension and road holding by keeping low gains of $\dot{z}_{\text {def }}$ and $z_{u s}-z_{r}$, a not common feature of this controller when is applied without the dynamic saturation, see Do et al. (2010). The $H_{\infty}$ controllers does not kept a safety condition for $\dot{z}_{d e f}$, see Fig. 14, (top plot) for suspension deflection and (bottom plot) for road holding.
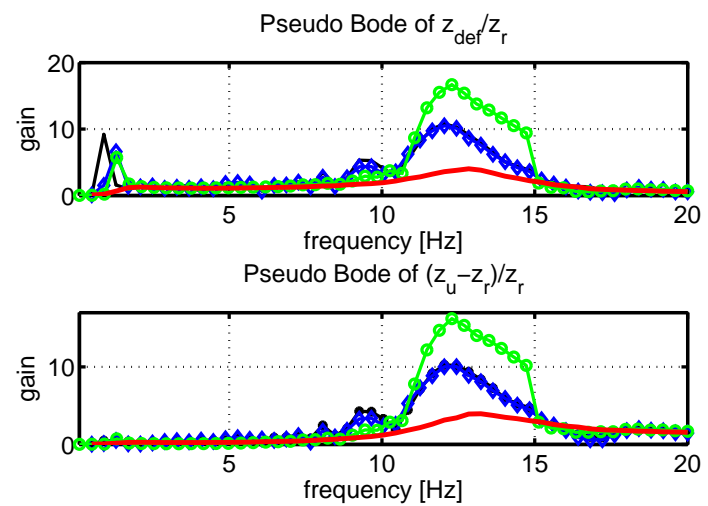

Fig. 14. Pseudobodes for the performance objectives.

Realistic applied current. The controllers for $\zeta_{M R}$ medium and high exposes a windup effect in actuation. The controller with $\zeta_{M R}$ low does not show current saturation but the manipulation is less effective than the exposed by the $S H-A D D$, Fig. 15, (top plot). In another example, over [15] $\mathrm{Hz}$, by applying low level current, the $S H-A D D$ sets a low damping suspension. Fig. 15, (bottom plot).

Dynamic saturation effect. For $[2-5] \mathrm{Hz}$ the maximum velocities are small, and the $H_{\infty}$ controllers designed with $\zeta_{M R}$ medium and high try to achieve the desired force applying the maximum current. The $S H-A D D$ and $H_{\infty}$ controller $\zeta_{M R}$ low has a similar behavior, Fig. 16, (top plot). For instance, with higher maximum velocities, the saturation is left out and the controllers delivers variable forces. The problem is that such forces are active not semi-active. The $S H$ - $A D D$ controller remains in the semi-active zone. This can be observed in Fig. 16, (bottom plot) where the $S H$ - $A D D$ generated force has a phase shift approximated to $\pi$. In this 

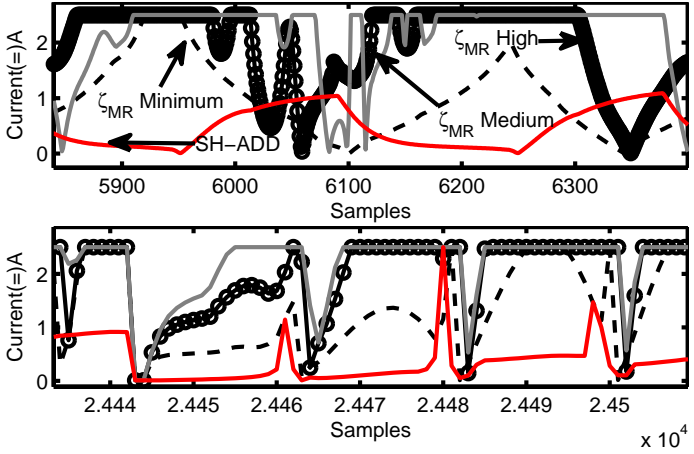

Fig. 15. Current applied to QoV by the evaluated controllers. Top plot shows saturation effect at frequencies below $5 \mathrm{~Hz}$. Bottom plot exposes the current generated at high frequencies.

simulation, the $H_{\infty}$ controllers are not a feasible solution for frequencies over $10 \mathrm{~Hz}$.
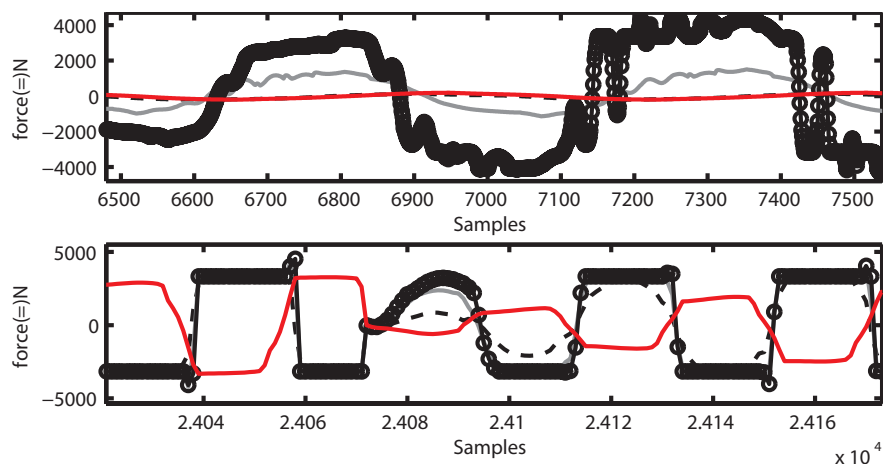

Fig. 16. Saturation effect on the dissipative force.

The scheduling parameter $\rho^{*}$ is always positive, Fig. 17 , and when $\rho$ has a specific value, $\rho^{*}$ could take a lower values due to the dynamic saturation.

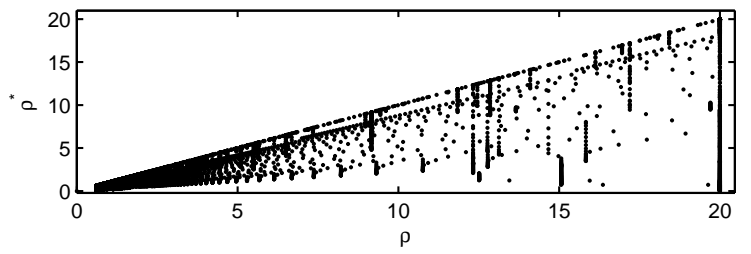

Fig. 17. Scheduling parameter $\rho^{*}=\rho \cdot \rho_{\text {sat }}$ versus $\rho$ map generated during the $H_{\infty}$ maximum damping controller closed loop test.

The presented results shows that the saturation influences the performances in a complex manner. The linear controllers in the $H_{\infty}$ framework are not enough for this automotive system. Also, the modification done to the $\mathrm{SH}$ $A D D$ approach, by the product $I \cdot \dot{z}_{\text {def }}$ instead of the desired damping ratio, and applying in cascade the dynamic saturation formulation, a smoother manipulation can be obtained. This is a desired condition in real applications.

This works opens the possibility of a $L P V$ controller with one scheduling parameter for a quarter of car, including the nonlinearities and dynamic saturation of the $M R$ damper, a challenging task in the literature.

\section{CONCLUDING REMARKS}

The presented work deals with the definition of a quarter of car structure, proper for $L P V$ controller synthesis where one scheduling parameter will allow to reduce the conservatism, a challenging issue in semi-active suspension. The simulation results show that the dissipativity constraint and the dynamic saturation should be included on the scheduling parameter in order to be taken into account in the controller synthesis and in the performances objectives.

The dynamic saturation formulation with the maximum velocity $\dot{z}_{\text {def }}$ allows to apply a weighting value to the controllers output, the results for the evaluated controllers shows how the windup effect can be coped.

As further work in a first step, the weighting functions of each controller could be optimized through a genetic algorithm where an anti-windup strategy will be included. The inclusion of the hysteresis in the model is also under study. The design of a LPV controller with the optimal weighting functions is the last step.

\section{REFERENCES}

Apkarian, P. and Gahinet, P. (1995). A Convex Characterization of Gain-Scheduled $\mathrm{H}$ inf Controllers. IEEE Trans. on Automatic Control, 40-5, 853-864.

Bastow, D., Howard, G., and Whitehead, J.P. (2004). Car Suspension and Handling. SAE.

Do, A.L., Sename, O., and Dugard, L. (2010). An LPV Control Approach for Semi-Active Suspension Control with Actuator Constraints. In American Control Conference June 30-July 02, 2010, Baltimore, MD. Accepted.

Guo, S., Yang, S., and Pan, C. (2006). Dynamical Modeling of Magneto-rheological Damper Behaviors. Int. Mater, Sys. and Struct., 17, 3-14.

Lozoya-Santos, J., Morales-Menendez, R., and RamirezMendoza, R. (2009). Design of Experiments for MR Damper Modelling. In Neural Netwotks, Int. Joint Conf. on, IEEE Proc.

Poussot-Vassal, C., Sename, O., Dugard, L., Gáspár, P., Szabó, Z., and Bokor, J. (2008). A New Semi-active Suspension Control Strategy through LPV Technique. Control Engineering Practice, 16(12), 1519-1534.

Savaresi, S.M., Silani, E., Bittanti, S., and Porciani, N. (2003). On Performance Evaluation Methods and Control Strategies for Semi-Active Suspension Systems. In Proceedings of the 42nd IEEE Conference on Decision and Control, Maui, Hawaii USA, December.

Savaresi, S. and Spelta, C. (2007). Mixed Sky-Hook and ADD: Approaching the Filtering Limits of a Semi-Active Suspension. J. Dyn. Sys., Meas., Control, 129(4), 382392. 